\title{
A Simple Conceptual Model for Estimating the First Bending Natural Frequency of Bridge Superstructures
}

\author{
Farnoush Karimi, ${ }^{1}$ Reza Akbari ${ }^{D},{ }^{2}$ and Shahrokh Maalek ${ }^{3}$ \\ ${ }^{1}$ Department of Engineering, Isfahan (Khorasgan) Branch, Islamic Azad University, Isfahan, Iran \\ ${ }^{2}$ Road Maintenance Department, Road Maintenance and Transportation Organization, Tehran, Iran \\ ${ }^{3}$ School of Civil Engineering, College of Engineering, University of Tehran, Tehran, Iran \\ Correspondence should be addressed to Reza Akbari; rakbari@ut.ac.ir
}

Received 21 July 2021; Revised 20 December 2021; Accepted 27 January 2022; Published 25 February 2022

Academic Editor: Yuanping XU

Copyright (C 2022 Farnoush Karimi et al. This is an open access article distributed under the Creative Commons Attribution License, which permits unrestricted use, distribution, and reproduction in any medium, provided the original work is properly cited.

\begin{abstract}
Several parameters affect the bridge's natural frequencies while parameters related to the geometric characteristics of bridge components are more important. Maximum span length (SL) (length of the main or longest span), deck width, number of girders and spans, and girder's height can be regarded as the main influencing parameters. In this paper, the first bending natural frequency (FBNF) of bridge superstructures of typical structural systems is assessed analytically using a simple conceptual model considering the main analytical parameters. The results show that the FBNF of bridges is strongly related to the SL of the longest span. It means that the other parameters are considered indirectly and may not be essentially considered as influencing parameters.
\end{abstract}

\section{Introduction}

Assessing the bridge superstructures' natural frequencies via a simplified approach is a subject matter of interest for decades. This is carried out in order to quantify the main dynamic characteristics of bridges as key issues in recognition of their dynamic behavior as well as the key parameters influencing the bridges' service life. Even a rough quantification and estimation is important for bridge designers or engineers to better understand the dynamic characteristics of the structure under consideration. $\mathrm{Nu}-$ merical modeling and analysis or conducting the conventional vibration tests can be regarded as complex and more accurate methods. In the past two decades, many research studies on the dynamic testing of bridges have been reported.

When the response of the superstructure is only considered, in between the natural frequencies of bridges in different vibration modes, the first bending mode (FBM) is more important. It appears as the fundamental natural frequency for the entire isolated superstructures and bridges of short piers even under the condition of integral structural systems. The first bending natural frequency (FBNF) has another important application of determining the allowable bridge girders' vertical deflection against dynamic live loads and of developing new impact factors for bridge design purposes.

For instance, according to the AASHTO Standard Specifications [1], the maximum midspan vertical deflection is restricted to a given relative value of span length (SL) to avoid excessive vibrations which is related to the FBNF (e.g., $1 / 800$ of SL for ordinary bridges and 1/1000 for urban bridges). Some other codes such as the Canadian or Australian codes ([2]; AS5100, 2004) do not explicitly limit liveload deflections, and a different approach is used. In these codes, a relationship between the FBNF of the bridge deck and its live-load vertical deflection is defined to limit the vertical deflection (for example, see Figure 1). In the Australian code, a simple equation (discussed in the following) taken from beam vibration response is suggested for determining the FBNF of simple-span (noncontinuous) bridges. 


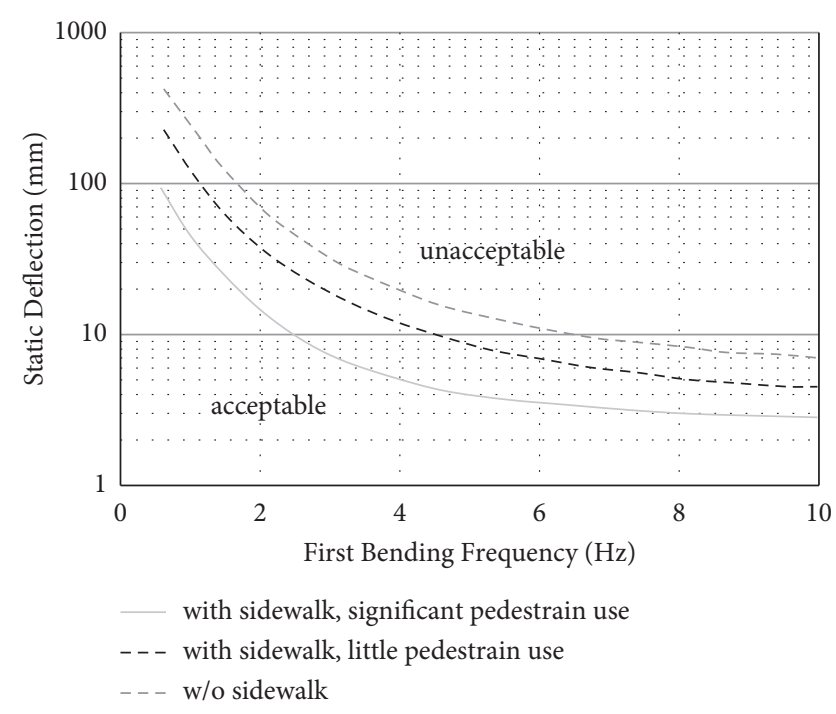

Figure 1: Deflection limitation according to the Australian standard.

As a result, developing a relationship in the form of a simple and approximate equation for determining the FBNF of bridges is important.

In this paper, on the basis of the formulae available in the literature and summarized or reviewed here, the influence of the main geometric characteristics of bridges has been investigated in order to estimate the FBNF. A mathematical simplification on the theory of free vibration of beams/plates has been presented to identify the most important parameters. According to the obtained results, the obtained formulae have also been compared with those reported by previous researchers.

\section{Background}

Rather than bridges and frame buildings, deriving a simplified fundamental frequency formulation for different types of special structures is a common and active research area. For instance, Bayraktar et al. [4] conducted in situ dynamic tests for this purpose in the case of masonry stone minarets. Calik et al. [5] performed ambient vibration tests in order to obtain an empirical formulation for estimating the fundamental frequency of historical stone mosques with masonry domes. Bartoli et al. [6] collected a large amount of data from a literature review and used those data to identify the key parameters affecting the dynamic behavior of masonry towers. Semiempirical formulations were proposed for determining the natural frequency of masonry towers. Lopez et al. [7] proposed formulae for estimating the fundamental frequencies of masonry churches through numerical regressions between the results of experimental tests taken from the literature and finite element analyses.

In the case of bridges, because of the complexity and diversity of the structural systems, deriving a simple mathematical formula for determining the FBNF with sufficient level of accuracy for a wide variety of deck systems of different number of spans and boundary conditions may seem difficult. Tens of research studies have been previously carried out, and several relations defining the FBNF of bridges of different superstructure systems have been proposed. Generally, by reviewing the research results available in the literature and without describing each of which in detail through a typical one-by-one literature review, the final formulae suggested in the past as well as a summary of the related conditions or limitations have been outlined. The results are given in Table 1 (see [21]). In order to better compare the proposed formulae, the formulae are drawn in Figure 2 for SLs between $10 \mathrm{~m}$ and $100 \mathrm{~m}$.

In Table $1, L$ is the maximum SL (MSL) in meters, $f_{1}$ and $T_{1}$ are the natural frequency and period of the FBM (in $\mathrm{Hz}$ and $s$ ) and $f_{1}=1 / T_{1}, D$ is the depth of girders $(\mathrm{m})$, and $w$ is the deck width.

It can be seen that the relationships presented by Karimi et al. [22] and Akbari et al. [21] may be considered as the upper band, the lower band, and the middle line among the proposed formulae for spans longer than $20 \mathrm{~m}$. It is also clear that the dispersion of the results reduces while the MSL increases. It is because of this fact that the dynamical response of the FBM of bridge superstructures of short-span bridges highly depends on the geometric parameters of the deck and its structural system. While some of the proposed formulae have been developed for MSLs shorter than those shown in Figure 2, good agreements are shown for the other ranges of the SLs.

According to Table 1, the parameter MSL is the main influencing parameter (except for the formulae suggested by Dusseau and by Karimi et al., where the height of the girder or the deck width has been also used). Also, the presence of a relation between the FBNF and the MSL of the bridge is quite evident. On the other hand, the general equation form that mainly accommodates the formulae presented in $\mathrm{Ta}$ ble 1 is $f_{1}=\alpha L^{\beta}$. In each proposed formula, the constant parameters $\alpha$ and $\beta$ are usually obtained through regression analysis on a gathered set of experimentally or numerically obtained data.

\section{Beam or Plate Simplified Model}

The physical model which corresponds to a typical slab-ongirder bridge is a thin plate with longitudinal stiffeners, the edges perpendicular to the direction of traffic being simply supported (SS) and the other two edges remaining free or elastically supported. On the basis of beam's and plate's theory of free vibration, the FBNF of a uniform cross section of a single-span beam and plate physical model is presented by the following relations:

$$
\begin{aligned}
& f_{1}=\lambda \sqrt{\frac{E I}{\rho L^{4}}}, \quad \text { for beams, } \\
& f_{1}=\lambda \sqrt{\frac{D}{\rho a^{4}}}, \quad \text { for plates, }
\end{aligned}
$$

where $\lambda$ represents a parameter (nondimensional) related to support conditions; $D$ and $E I$ represent, respectively, the 
TABLE 1: List of the formulae suggested in the past to estimate the FBNF of bridges.

\begin{tabular}{|c|c|c|c|}
\hline Formula & Coverage of bridge type & Coverage of the SL & Developer \\
\hline$f_{1}=105.3 L^{-1}\left(\right.$ or $\left.T_{1}=0.0095 L\right)$ & NS & NS & [8] \\
\hline$f_{1}=128.2 L^{-1}\left(\right.$ or $\left.T_{1}=0.0078 L\right)$ & Steel bridges & $10 \leq L \leq 30$ & [9] \\
\hline$f_{1}=76.36 L^{-1}\left(\right.$ or $\left.T_{1}=0.0131 L\right)$ & NS & NS & {$[10]$} \\
\hline$f_{1}=-0.21 L+10.3$ & NS & $15 \leq L \leq 30$ & {$[11]$} \\
\hline$f_{1}=110 L^{-1}$ & NS & $15 \leq L \leq 120$ & [12] \\
\hline$f_{1}=95.4 L^{-0.933}$ & NS & $10 \leq L \leq 110$ & [13] \\
\hline$f_{1}=90.6 L^{-0.933}$ & NS & $10 \leq L \leq 110$ & [14] (equation (1)) \\
\hline$f_{1}=100 L^{-1}+0.6$ & NS & $10 \leq L \leq 110$ & [14] (equation (2)) \\
\hline$f_{1}=100 L^{-1}$ & NS (LL) & NS & [14] (equation (3)) \\
\hline$f_{1}=82 L^{-0.9}$ & NS & $10 \leq L \leq 180$ & {$[15]$} \\
\hline$f_{1}=33.6 L^{-0.73}$ & Footbridges & NS & [16] \\
\hline$f_{1}=217 L^{-1.431} \sim 112 L^{-0.925}$ & Footbridges & NS & {$[17]$} \\
\hline$f_{1}=588.118 L^{-1.45} D^{-0.4}$ & Steel I-girder bridges & $60 \leq L \leq 70$ & {$[18]$} \\
\hline$f_{1}=80 L^{-1}$ & Railway bridges (lower limit) & $4 \leq L \leq 20$ & [19] (equation (1)) \\
\hline$f_{1}=23.58 L^{-0.592}$ & Railway bridges (lower limit) & $20 \leq L \leq 100$ & [19] (equation (2)) \\
\hline$f_{1}=47.59 L^{-0.81}$ & Steel I-girder bridges & $20 \leq L \leq 85$ & [20] (equation (1)) \\
\hline$f_{1}=192.4 L^{-1.15}$ & Prestressed concrete I-girder bridges & $20 \leq L \leq 40$ & [20] (equation (2)) \\
\hline$f_{1}=30.73 L^{-0.63}$ & Prestressed concrete box-girder bridges & $10 \leq L \leq 140$ & [20] (equation (3)) \\
\hline$f_{1}=20.75 L^{-0.57}$ & Steel box-girder bridges & $25 \leq L \leq 120$ & [20] (equation (4)) \\
\hline$f_{1}=110 L^{-1} \pm 10 \%$ & NS & $10 \leq L \leq 150$ & {$[21]$} \\
\hline$f_{1}=273 L^{-1.4412} w^{0.1104}$ & Concrete I-girder bridges & $10 \leq L \leq 35$ & [22] (equation (1)) \\
\hline$f_{1}=51.162 L^{-0.728} w^{0.023}$ & Steel and concrete I-girder bridges & $10 \leq L \leq 35$ & [22] (equation (2)) \\
\hline$f_{1}=43.27 L^{-0.746} w^{0.170}$ & Arch bridges & $10 \leq L \leq 35$ & [22] (equation (3)) \\
\hline
\end{tabular}

NS $=$ not specified.

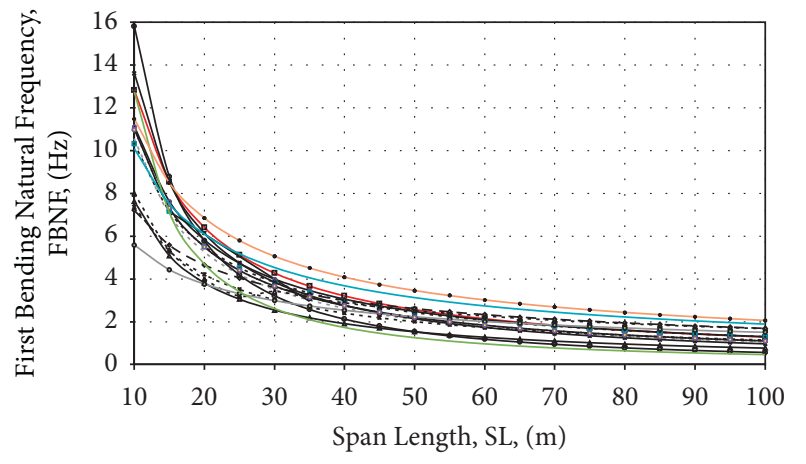

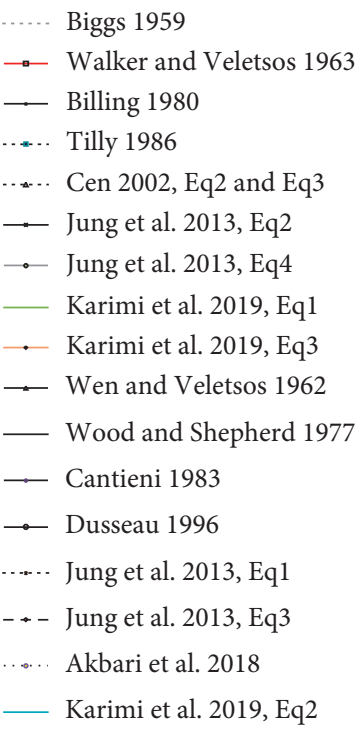

FIgURE 2: Comparison of the formulae suggested in the past to estimate the FBNF of bridges. 
bending rigidity of the plate and beam; $E$ and $I$ represent the modulus of elasticity and beam section's moment of inertia; and $L$ and $a$ are the length of the beam and the free edge length of the plate. $\rho=\gamma A$ for materials of mass density $\rho$, specific mass $\gamma$, and cross-sectional area $A$. Warburton [23] and Leissa [24] presented the exact solutions as well as equations for the natural frequency of beams and plates for different support conditions.

In an equivalent and unit width strip of a beam of uniform thickness $h, I=h^{3} / 12$. Also, in an equivalent and unit width plate strip of uniform thickness $t$ and Poisson's ratio $v, D=E t^{3} / 12\left(1-v^{2}\right)$. For SS plates of rectangular shape and free edges, the parameter $a$ represents the free edge length. For medium-to-long-span bridges of large length-to-depth ratios with the same boundary conditions, when FBNF is concerned, the Euler-Bernoulli beam theory is usually used with sufficient level of accuracy. As a result of this simplification, in the case of free vibration of an equivalent unit width strip of the plate, the bottom and top levels experience a beamlike deformation and the flexural rigidity parameter $D=E t^{3} / 12$.

Besides the fact that bridge decks generally follow the theory of orthotropic plates, the dynamical response for the FBM of girder-type superstructure systems of medium-tolong spans is described with good agreements with the beams' theory. Therefore, substituting the latter quantities in equations (1) and (2) results in

$$
\begin{aligned}
f_{1} & =\frac{\lambda}{2 \pi} \sqrt{\frac{E h^{3} / 12}{\gamma h L^{4}}} \\
& =\frac{\lambda}{2 \pi} \sqrt{\frac{E}{12 \gamma}} \frac{h}{L^{2}} \\
& =C \frac{h}{L^{2}} \stackrel{\text { yields }}{\longrightarrow} f_{1} \propto \frac{h}{L^{2}},
\end{aligned}
$$

where $f_{1}$ is the FBNF. As shown, the quantity $C$ relates to the properties of materials as well as the support conditions. The other geometrical parameters $L$ and $h$ can be regarded as the two main influencing factors in the FBNF with abovementioned assumptions. Barth and $\mathrm{Wu}$ [25] showed that the $L / h$ ratio influences the FBNF of bridges considerably.

In the following, it is shown that when loadings and material properties are known, in typical strength-based designs (i.e., bending and shear design) of rectangular crosssection beams of uniform loading, the quantity $L / h$ depends on the loading quantity and material properties and can be assumed as a constant.

Suppose a unit width strip of the SS beam with length $L$ and thickness $h$ under uniformly distributed loading per unit length of $W$. Consider $V$ and $M$ as the maximum shear force and bending moment in which $V=W L / 2$ and $M=W L^{2} / 8$. As conceptual design processes for steel and concrete members are different, the following standard design procedure is used in typical designs.

\subsection{Design for Steel Members}

3.1.1. Shear Design. The maximum shear stress can be simply calculated as follows:

$$
\tau_{\max }=1.5 \frac{\mathrm{V}}{\mathrm{A}}=1.5 \frac{\mathrm{WL} / 2}{h}=0.75 \mathrm{~W} \frac{\mathrm{L}}{\mathrm{h}} .
$$

However, allowable shear stress depends on steel yield or ultimate strength as follows:

$$
\tau_{\text {all }} \propto\left(F_{y} \text { or } F_{u}\right),
$$

where $\tau_{\text {all }}$ and $\tau_{\max }$ are, respectively, the allowable and maximum shear stresses. $F_{y}$ and $F_{u}$ are the yield and ultimate strength of steel. Equalizing the two abovementioned shear stresses, regardless of strength reduction factors in different codes, results in

$$
\frac{L}{h} \propto\left(W, F_{y} \text { or } F_{u}\right)
$$

3.1.2. Bending Design. The maximum bending stress can be simply calculated as follows:

$$
F_{b(\max )}=\frac{M}{S}=\frac{6}{8} w\left(\frac{L}{h}\right)^{2}
$$

However, allowable bending stress depends on steel yield or ultimate strength as follows:

$$
F_{b(\text { all })} \propto\left(F_{y} \text { or } F_{u}\right),
$$

where $F_{b(\text { all })}$ and $F_{b(\max )}$ are, respectively, the allowable and maximum bending stresses and $S$ is the section modulus. Equalizing the two abovementioned bending stresses, regardless of strength reduction factors in different codes, results in

$$
\left(\frac{L}{h}\right)^{2} \propto\left(W, F_{y} \text { or } F_{u}\right)
$$

\subsection{Design for Concrete Members}

3.2.1. Shear Design. The shear capacity of reinforced concrete beams can be simply related as follows:

$$
V_{u} \equiv \rho_{s} d F_{y}+V_{c} \equiv \rho_{s} h F_{y}+\sqrt{f_{c}} h F_{y},
$$

where $V_{c}$ and $V_{u}$ indicate the shear capacity of the concrete beam and shear demand, respectively, $d$ represents the effective section height, and $f_{c}$ and $\rho_{s}$ represent the concrete compressive strength and shear reinforcement ratio, respectively. Equalizing the shear capacity of the beam with the maximum shear force imposed $(\mathrm{V}=\mathrm{WL} / 2)$, regardless of strength reduction factors in different codes, results in

$$
\frac{L}{h} \propto\left(W, F_{y}, f_{c}, \rho_{s}\right) \text {. }
$$

3.2.2. Bending Design. The bending capacity of concrete beams can be simply related as follows: 


$$
M_{u} \equiv \rho_{b} h^{2} F_{y}\left(1-0.59 \rho_{b} \frac{F_{y}}{f_{c}}\right),
$$

where $M_{u}$ is the bending capacity of the reinforced concrete beam and $\rho_{b}$ is the bending reinforcement ratio (a percent of equivalent steel ratio). Equalizing the bending capacity of the beam with the maximum bending force imposed $\left(M=W L^{2} / 8\right)$, regardless of strength reduction factors in different codes, results in

$$
\left(\frac{L}{h}\right)^{2} \propto\left(W, F_{y}, f_{c}, \rho_{b}\right) .
$$

It can be concluded here that, by considering the abovementioned reliable assumptions, in typical steel and concrete design of beams, the term $L / h$ depends on the loading quantity and material properties and can be assumed as a constant in a bridge. Therefore, according to the conventional design practice for SS beams, equation (3) in parallel with the abovementioned results shows that the term $h / L$ can be assumed as a constant parameter and the FBNF can be written as

$$
f_{1} \propto \frac{1}{L} \text {. }
$$

Equation (14) shows that the FBNF of a SS beam is inversely related to the SL of the beam, and this relation is valid for multispan continuous beams. This can be regarded as the main philosophy and conceptual model in support of the suggested formulae as mentioned previously. The proposed formulae (see Table 1) are usually determined by performing regression analyses on the results of a set of fullscale dynamic tests of bridges or numerical analyses of bridge finite element models.

\section{Bridge Design Applications}

With reference to previous equations, the FBNF may be rewritten by

$$
f_{1}=\frac{\lambda}{2 \pi} \sqrt{\frac{E I}{\gamma A L^{4}}}=\frac{\lambda}{2 \pi} \sqrt{\frac{E}{\gamma L^{4}}} \sqrt{\frac{I}{A}} \equiv B \sqrt{\frac{I}{A}} .
$$

The new parameter $B$ depends on the support conditions, properties of materials, and the SL. The term $\sqrt{\mathrm{I} / \mathrm{A}}$ represents the deck cross section's radius of gyration (ROG).

For SS end conditions, by equalizing $f_{1}=\alpha L^{\beta}$ with equation (15), we may write

$$
f_{1}=\frac{\pi}{2} \sqrt{\frac{E}{\gamma L^{4}}} \sqrt{\frac{I}{A}} \cong \alpha L^{\beta} .
$$

Or,

$$
\sqrt{\frac{I}{A}}=\frac{2 \alpha}{\pi} L^{\beta+2} \sqrt{\frac{\gamma}{E}}
$$

Equation (17) indicates a relationship between the ROG of a SS superstructure and the properties of materials and the SL. $\alpha$ and $\beta$ are also given in Table 1 for different proposed formulae.
In normal bridge design practice, at an early design stage, some important decisions as to the SLs, support conditions, and properties of materials of the bridge deck are carried out. Equation (17) may be applied for estimating the cross section's geometrical parameters of the superstructure. Variation of the ROG parameter, $\sqrt{I / A}$, with respect to $\mathrm{SL}$ and $L$ are drawn in Figure 3. The formulae suggested for railway and footbridges are not shown. It has been assumed here that $\gamma=25 \mathrm{kN} / \mathrm{m}^{3}$ and $E=25 e 6 \mathrm{kN} / \mathrm{m}^{2}$ for concrete. In Table 2, the relationships associated with the previously suggested relations are shown.

Figure 3 indicates that for SLs less than $50 \mathrm{~m}$, there is a good agreement between the various suggested formulae. The figure also indicates that the dispersion increases for some of the formulae by increasing the SL from 40 to 50 meters. It is because of this fact that for SL larger than 40 to 50 meters, the normal superstructure systems such as slabon-girder are not used as the main load-carrying system. Instead, prestressed box-girder or cable-supported decks are usually used. When the latter systems are used, the geometrical parameters of the deck cross section not essentially represent the characteristics of the main load-carrying system.

It can be concluded here that, in the initial steps of a bridge design case study, selecting section properties with larger values for ROG than those summarized in Table 2 indicates the likelihood of overestimation in the initial design and lesser values indicate the probability of underestimation, compared with existing bridges. These formulae can be extended and developed for other types of boundary conditions.

\section{Bridge-Widening Applications}

Another application for the abovementioned approximate formulae is bridge widening. Maadani et al. [26] investigated a special bridge-widening case study in which the new superstructures have been constructed close to the existing superstructure with no structural connection along the longitudinal joint. This joint is usually sealed and covered by a continuous pavement over the two parts. The most important design issue is that special consideration and measures should be taken into account about the dynamic interaction through the longitudinal joint between the existing and the new parts. It is clear that the existing and new parts along the longitudinal joint usually have complex interactions that may affect the dynamic and vibration behavior of the whole superstructure. This may cause damage to the bridge, especially in steel-welded and -bolted connections because of fatigue problems. As a result, not only the standard design specifications should be satisfied for the widened bridge, but also the dynamical response of the whole bridge and associated dynamic properties of the new bridge should be close to those of the existing bridge. Maadani et al. [26] investigated this point by applying several ambient vibration tests on a bridge-widening project.

Equation (15) indicates that the FBNF of the two structures are identical provided that support conditions, properties of materials, SLs, and ROG of deck cross sections 


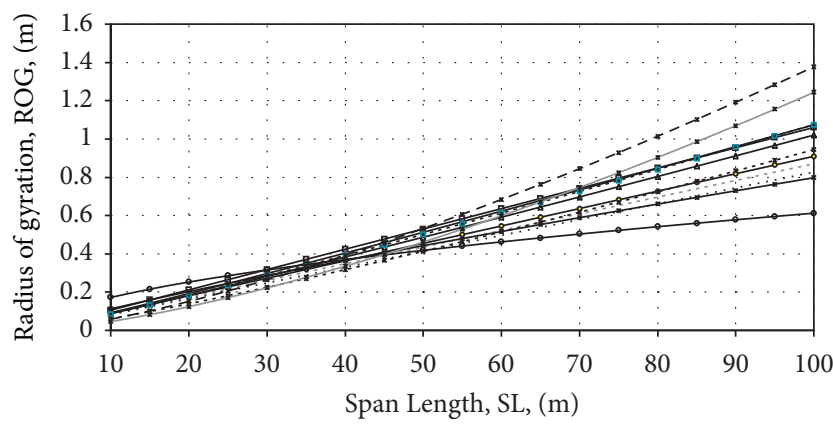

$$
\begin{aligned}
& \ldots . . \text { Biggs } 1959 \\
& \ldots \text { Billing (1979) or Akbari et al. (2018) } \\
& \ldots \text { Cantieni 1984, Eq1 } \\
& \ldots \ldots \text { Tilly (1986) } \\
& \ldots \ldots \text { Jung et.al. (2013), (F1) } \\
& \ldots \text { Jung et.al. (2013), (F3) } \\
& \rightarrow \text { Walker and Veletsos } 1963 \\
& \ldots \text { Cantieni (1983) } \\
& \ldots \text { Cantieni 1984,Eq3 } \\
& \rightarrow \text { Dusseau (1996), (for D=2m) } \\
& \rightarrow \text { Jung et.al. (2013), (F2) } \\
& \rightarrow \text { Jung et.al. (2013), (F4) }
\end{aligned}
$$

\begin{tabular}{|c|c|c|c|}
\hline Formulae proposed for the FBNF as indicated in Table 1 & $\alpha$ & $\beta$ & $\sqrt{I / A}$ \\
\hline$f_{1}=105.3 L^{-1}$ & 105.3 & -1 & $67 L$ \\
\hline$f_{1}=128.2 L^{-1}$ & 128.2 & -1 & $81.6 L$ \\
\hline$f_{1}=110 L^{-1}$ & 110 & -1 & $70 L$ \\
\hline$f_{1}=95.4 L^{-0.933}$ & 95.4 & -0.933 & $60.73 L^{1.067}$ \\
\hline$f_{1}=100 L^{-1}+0.6$ & 90.6 & -0.933 & $57.68 L^{1.067}$ \\
\hline$f_{1}=100 L^{-1}$ & 100 & -1 & $63.66 L$ \\
\hline$f_{1}=82 L^{-0.9}$ & 82 & -0.9 & $52.2 L^{1.1}$ \\
\hline$f_{1}=33.6 L^{-0.73}$ & 33.6 & -0.73 & $21.4 L^{1.27}$ \\
\hline$f_{1}=588.118 L^{-1.45} D^{-0.4}(D=2 \mathrm{~m})$ & 588.118 & -1.45 & $374.4 L^{0.55}$ \\
\hline$f_{1}=80 L^{-1}$ & 94.76 & -0.748 & $60.33 L^{1.252}$ \\
\hline$f_{1}=47.59 L^{-0.81}$ & 47.59 & -0.81 & $30.3 L^{1.19}$ \\
\hline$f_{1}=192.4 L^{-1.15}$ & 192.4 & -1.15 & $122.49 L^{0.85}$ \\
\hline$f_{1}=30.73 L^{-0.63}$ & 30.73 & -0.63 & $19.29 L^{1.37}$ \\
\hline$f_{1}=20.75 L^{-0.57}$ & 20.75 & -0.57 & $13.21 L^{1.43}$ \\
\hline$f_{1}=110 L^{-1} \pm 10 \%$ & 109.9 & -1 & $70 L$ \\
\hline
\end{tabular}

FIgURE 3: Variation of the ROG parameter, $\sqrt{I / A}$, with SL and $L$ for different formulae.

TABLE 2: The relationship between ROG, $\sqrt{I / A}$, and SL, $L$, and the associated parameters $\alpha$ and $\beta$ for different formulae.

are equal. In the bridge design process for widening proposes, considering the same values and properties for the SLs, properties of materials, and support conditions for the existing and new parts, in order to obtain identical values for the FBNF, the bridge designer should attempt to find a value for the geometrical index (GI), $I / A$, for the new part to be equal to the existing part. In the design of the newly widened superstructure, as an early approximation, the superstructure section properties are chosen in which equal values for GI are obtained. In the case of no as-built construction drawings, equation (17) together with the relations in Table 2 can be used to estimate the GI.

As a result, the following offer may be prepared to designers.
For bridge-widening projects, when the newly widened part is constructed as a new and independent bridge, maximum effort should be made to obtain identical support conditions, properties of the material, SLs, and GI.

Therefore,

$$
\left(f_{1}\right)_{\text {new deck }}=\left(f_{1}\right)_{\text {existing deck }} \stackrel{\text { yields }}{\longrightarrow}\left(\frac{I}{A}\right)_{\text {new deck }}=\left(\frac{I}{A}\right)_{\text {existing deck }} .
$$

The flowchart in Figure 4 is proposed in the case of widening projects:

As noted above, a special case of bridge-widening project has been examined by the abovementioned index and fully described with verification by dynamic tests (see [26]). 


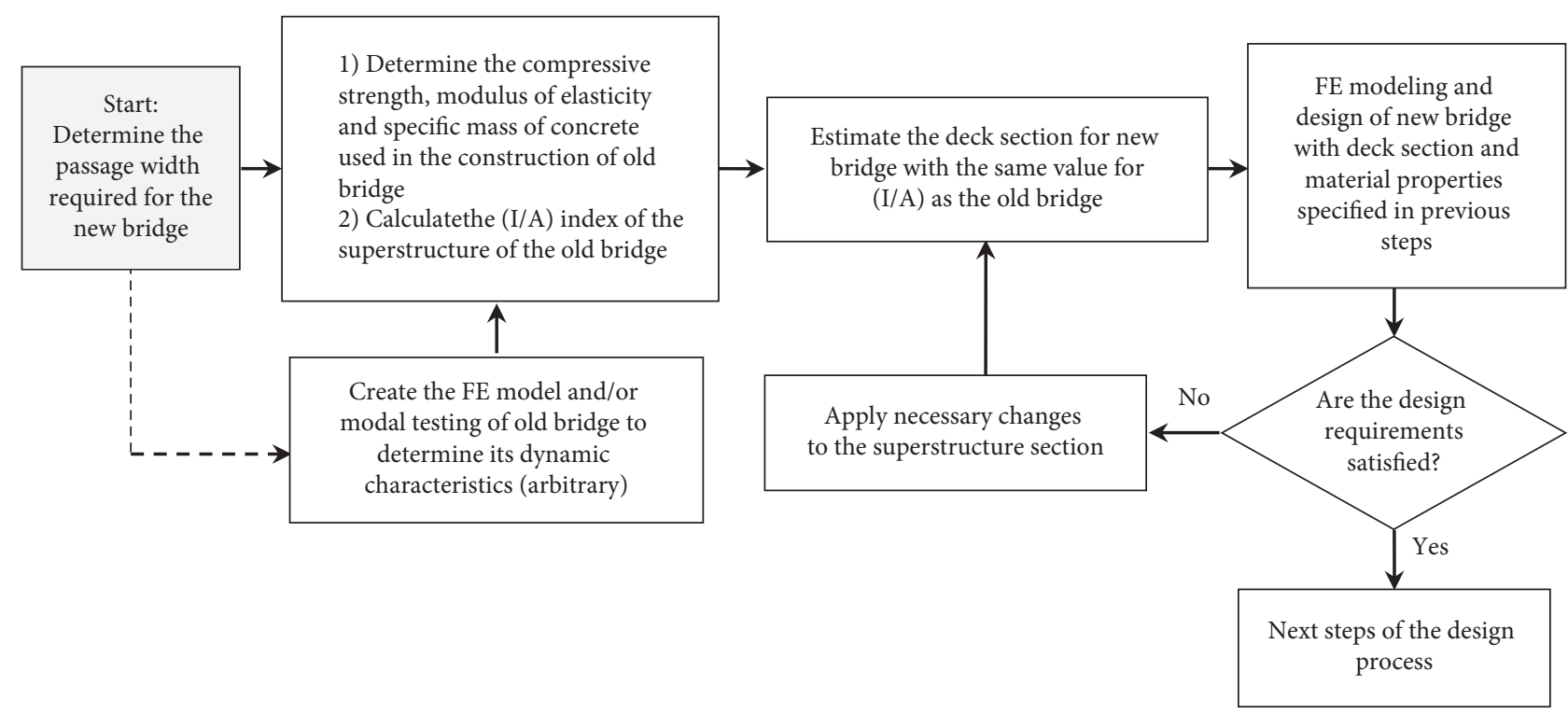

FIGURE 4: The proposed flowchart in bridge-widening design projects.

Validation of the content has been fully obtained in the abovementioned paper.

\section{Conclusion}

In this article, the suggested formulae available in the literature for estimating the FBNF of bridge superstructures have been re-reviewed and the methodology for obtaining these formulae has been explained. Through a simple conceptual model for estimating the FBNF of bridge superstructures, another simple formula has been developed and its efficiency has been compared. The proposed formula has been reconsidered to reproduce a new empirical formula useable to estimate the superstructure cross-section dimensions of simple-span bridges. This can be used in bridge design practice in the initial steps, particularly for bridgewidening purposes.

The results of the present work have been summarized as follows:

(i) The FBNF of bridge superstructures is mainly sensitive to their SL of the longest span. Hence, the FBNF of bridge superstructures can be empirically or mathematically simplified as a function of bridge SL of the longest span.

(ii) For bridge-widening proposes, the designer is recommended to try to obtain deck cross-section dimensions in which the ROG or GI of two decks are equal as far as possible. This can lead to close FBNF and integral dynamical responses for the new bridge complex.

(iii) Despite the simplicity of the formulae investigated in this paper, they can be used for different superstructure types.

(iv) As the SL decreases, the sensitivity of the FBNF increases. Hence, the proposed formulae are not suitable for short-span superstructures.

\section{Data Availability}

All the data used in this work have been included in the article.

\section{Conflicts of Interest}

The authors declare that there are no conflicts of interest.

\section{References}

[1] AASHTO, American Association of State Highway and Transportation Officials, AASHTO LRFD Bridge Design Specification, AASHTO, Washington, WA, USA, 7th edition, 2014.

[2] Canadian Standards Association, Canadian Highway Bridge Design Code, Canadian Standards Association, Rexdale, Ontario, 1999.

[3] AS Standards Australia, Australian Standard AS 5100, Australian Standard for Bridge Design, Sydney, Australia, 2002.

[4] A. Bayraktar, İ. Çalik, and T. Türker, A Simplified Fundamental Frequency Formulation Based on In-Situ Tests for Masonry Stone Minarets, Springer, Berlin, Germany, 2021.

[5] İ. Çalik, A. Bayraktar, T. Türker, and M. Akköse, "Empirical formulation for estimating the fundamental frequency of historical stone mosques with masonry domes," The Structural Design of Tall and Special Buildings, vol. 29, no. 9, Article ID e1732, 2020.

[6] G. Bartoli, M. Betti, A. M. Marra, and S. Monchetti, "Semiempirical formulations for estimating the main frequency of slender masonry towers," Journal of Performance of Constructed Facilities, vol. 31, no. 4, 2017.

[7] S. Lopez, M. D'Amato, L. Ramos, M. Laterza, and P. B. Lourenço, "Simplified formulations for estimating the main frequencies of ancient masonry churches," Frontiers in Built Environment, vol. 5, 2019.

[8] J. M. Briggs, H. S. Suer, and J. M. Louw, "Vibration of simplespan highway bridges," Transactions of the American Society of Civil Engineers, vol. 124, no. 1, pp. 291-318, 1959. 
[9] W. H. Walker and A. S. Veletsos, Response of Simple-Span Highway Bridges to Moving VehiclesDepartment of Civil Engineering, University of Illinois, Urbana, IL, USA, 1963.

[10] R. K. Wen and A. S. Veletsos, "Dynamic behavior of simplespan highway bridges," in Proceedings of the 40th Annual Meeting of the Highway Research Board, Highway Research Board, pp. 1-26, Washington DC, USA, 1962.

[11] J. H. Wood and R. Shepherd, Vehicle Induced Vibration$s$ Ministry of Works and Development and the University of Auckland, Auckland, New Zealand, 1977.

[12] J. R. Billing and R. Green, "Design provisions for dynamic loading of highway bridges," Transportation Research Record, vol. 950pp. 94-103, Washington DC, USA, 1984.

[13] R. Cantieni, "Dynamic load tests on highway bridges in Switzerland-60 Years of experience," Report 211, Federal Laboratories for Testing of Materials (EMPA), Dübendorf, Switzerland, 1983.

[14] R. Cantieni, "Dynamic load testing of highway bridges," Transportation Research Record, Washington DC, USA, 1984.

[15] G. P. Tilly, Dynamic Behavior of Concrete Structures: Report of the Rilem 65 MDB Committee, Elsevier Science, Amsterdam, Netherlands, 1986.

[16] H. Bachmann, W. J. Ammann, and F. Deischl, Vibration Problems in Structures, Practical Guidelines, Birkhauser, Basel, Switzerland, 1995.

[17] M. Pirner and O. Fischer, "Wind-induced vibrations of concrete stress-ribbon footbridges," Journal of Wind Engineering and Industrial Aerodynamics, vol. 74-76, pp. 871-881, 1998.

[18] R. A. Dusseau, Natural Frequencies of Highway Bridges in the New Madrid Region, Final Report, Civil Engineering Department, Wayne State University, Detroit, MI, USA, 1996.

[19] CEN European Committee for Standardization, Eurocode 1: Actions on Structures - Part 2: Traffic Loads on Bridges, prEN 1991-2:2002, CEN, Brussels, Belgium, 2002.

[20] H. Jung, G. Kim, and C. Park, "Impact factors of bridges based on natural frequency for various superstructure types," KSCE Journal of Civil Engineering, vol. 17, no. 2, pp. 458-464, 2013.

[21] R. Akbari, S. Maadani, and S. Maalek, "On the fundamental natural frequency of bridge decks: review and applications," Proceedings of the Institution of Civil Engineers-Structures and Buildings, vol. 171, no. 12, pp. 931-945, 2018.

[22] F. Karimi, R. Akbari, and S. Maalek, "Assessment of the fundamental natural frequency of bridge decks," Asian Journal of Civil Engineering, vol. 20, no. 7, pp. 933-948, 2019.

[23] G. B. Warburton, The Dynamical Behavior of Structures, Pergamon Press, Oxford, UK, 1976.

[24] A. W. Leissa, "The free vibration of rectangular plates," Journal of Sound and Vibration, vol. 31, no. 3, pp. 257-293, 1973.

[25] K. E. Barth and H. Wu, "Development of improved natural frequency equations for continuous span steel I-girder bridges," Engineering Structures, vol. 29, no. 12, pp. 3432-3442, 2007.

[26] S. Maadani, R. Akbari, and S. Maalek, "Monitoring the dynamic characteristics of an urban bridge before, during and after widening," Structure and Infrastructure Engineering, vol. 11, no. 7, pp. 944-956, 2015. 